Supporting Information for

\title{
Ni-Nitrilotriacetic Acid Affinity SELEX Method for Selection of DNA Aptamers Specific to the N-Cadherin Protein
}

Luyan Yang, Tian Gao, Wenjing Li, Yu Luo, Salim Ullah, Xiaona Fang, Yanwei Cao*, Renjun Pei*

CAS Key Laboratory of Nano-Bio Interface, Suzhou Institute of Nano-Tech and Nano-Bionics, Chinese Academy of Sciences, Suzhou 215123, China

*Email: ywcao2017@sinano.ac.cn

*Email: rjpei2011@sinano.ac.cn 


\section{EXPERIMENTAL SECTION}

\section{Materials:}

Human His-tagged N-cadherin protein (Cat No. 11039-H08B) was purchased from Sino Biological Inc. (China). The HPLC-purified DNA library (Lib-40N-ncad) containing sequences with 40 random nucleotides (5'-ATACCAGCTTATTCAATT-N40-AGATAGTAAGTGCAATCT-3'), forward primer (FP1-ncad), reverse primer (RP2-ncad), 5'-FAM-labled forward primer (5'-FAM-FP1-ncad), biotinylated reverse primer (Biotin-RP2-ncad) with these sequences (5'-ATACCAGCTTATTCAATT-3'， 5'-AGATTGCACTTACTATCT-3', 5'-FAM-ATACCAGCTTATTCAATT-3' and 5'-Biotin-AGATTGCACTTACTATCT-3', respectively), and 5'-carboxyfluorescein (5'-FAM) modified sequences (Table 1) were synthesized by Sangon Biotech (China). Ni Sepharose ${ }^{\mathrm{TM}}$ Fast Flow was purchased from GE Healthcare (Sweden). Streptavidin-agarose beads and Power SYBRTM Green PCR Master Mix were purchased from Thermo Fisher Scientific (USA). Agarose was purchased from Biowest (Spain). Polymerase chain reaction (PCR) reagents including PCR buffer, dNTPs and rTaq polymerase, DNA marker and $6 \times$ loading buffer were

obtained from TaKaRa Biotechnology (China). SYBR ${ }^{\circledR}$ Green I dye was purchased from Invitrogen Technology (China). Prestained protein marker was purchased from Beyotime Biotechnology (China). Milli-Q water $(18.2 \mathrm{~K} \Omega \cdot \mathrm{cm})$ was used in all experiments.

\section{Q-PCR method}

Q-PCR was performed to analyze the amplification products of each enriched libraries as described previously. ${ }^{1,2}$ Thermal cycling parameters are 2 min at $50{ }^{\circ} \mathrm{C}, 10$ min at $95{ }^{\circ} \mathrm{C} ; 40$ cycles of $15 \mathrm{~s}$ at $94{ }^{\circ} \mathrm{C}, 15 \mathrm{~s}$ at $48{ }^{\circ} \mathrm{C}$ and $30 \mathrm{~s}$ at $72{ }^{\circ} \mathrm{C}$. And a melting experiment was performed from $42{ }^{\circ} \mathrm{C}$ to $92^{\circ} \mathrm{C}$.

\section{Enzyme-linked oligonucleotide assay}

To determine the interaction of DNA aptamer and N-cadherin, ELONA experiments were performed by attaching $10 \mathrm{pmol}$ of $\mathrm{N}$-cadherin to three contiguous wells of Corning $^{\circledR}$ 96-well. N-cadherin (solubilized in carbonate buffer $(\mathrm{pH} 9.6,0.05 \mathrm{mM}$ 
$\left.\mathrm{Na}_{2} \mathrm{CO}_{3} / \mathrm{NaHCO}_{3}\right)$ at $4{ }^{\circ} \mathrm{C}$ for $8 \mathrm{~h}$ ) was incubated with 60 pmol of FAM-labeled ssDNA aptamer $(0.6 \mu \mathrm{M}$ concentration in the final reaction volume of $100 \mu \mathrm{L})$ in SELEX buffer at RT for 90 min. After performing three wash steps with washing buffer to remove unbound sequences, the fluorescence intensity of each mixture was analyzed by exciting at $485 \mathrm{~nm}$ and measuring at $535 \mathrm{~nm}$ emission using PerkinElmer Victor 4 Microplate Reader (China).

\section{Cloning, sequencing and analyzing}

With the aim to clone individual aptamers present at the tenth round of SELEX, the products of PCR-amplified DNA were cloned using the pMD18-T Vector Cloning Kit (TaKaRa) and the recombinant plasmids were transformed into BL-21 E. coli.. Then, 29 individual DNA sequences were picked randomly and sequenced by Sangon Biotech (China). Then, we performed sequence homology analysis by Crustal x 1.8.3, molecular evolutional genetic analysis by Mega X10.0.5 and secondary structures prediction by NUPACK (http://www.nupack.org/).

\section{Dissociation constants of selected aptamers}

ELONA was established to assess the $K_{d}$ values of DNA aptamers. The fluorescence intensity of the reacted wells was used to determine the affinity, and detailed experimental methods were performed as described above. Plates (96-well) pre-washed with carbonate buffer were treated with $\mathrm{N}$-cadherin $(30 \mathrm{nM})$ at $4{ }^{\circ} \mathrm{C}$ for 8 h. Next, selected FAM-labeled aptamers of varying concentrations (5, 10, 50, 80, 100 and $125 \mathrm{nM}$ of each individual aptamer) were added into the microplate separately and incubated at RT for $90 \mathrm{~min}$. After washing, the fluorescence intensity was measured using PerkinElmer Victor 4 Microplate Reader. And the FAM-labeled initial library was used as negative control. All experiments were repeated 3 times.

The increase of the fluorescence intensity was expressed as mean \pm standard error and plotted against the aptamer concentration, and then the dissociation constant $\mathrm{K}_{\mathrm{d}}$ was evaluated by fitting the binding curve using the following equation:

$$
F-F_{0}=\frac{F_{\max } \cdot x}{K_{d}+x}
$$


Where $\mathrm{F}$ is the fluorescence intensity in each well after the interaction of FAM-DNA, and $F_{0}$ is the background fluorescence of the well coated by N-cadherin. $x$ is the concentration of aptamer, and the dissociation constant, $\mathrm{K}_{\mathrm{d}}$ was obtained by nonlinear fitting using Origin v8.0.

\section{Competitive fluorescent assay}

Competitive fluorescence assay is used to further investigate the binding capacity of aptamers. After pre-washing with $200 \mu \mathrm{L}$ of carbonate buffer, the 96-well microplate was coated with $10 \mu \mathrm{mol} / \mathrm{L}$ of target protein solution (diluted with carbonate buffer) and sealed at $4{ }^{\circ} \mathrm{C}$ overnight. Thereafter, different amounts of $\mathrm{N}$-cadherin $(0,10,25$, $30,50,75,100,125,150$, or $200 \mathrm{nmol} / \mathrm{L}$ ) and $200 \mathrm{nmol} / \mathrm{L}$ pre-treated FAM-modified aptamer (NS13) in $100 \mu \mathrm{L}$ of SELEX buffer were respectively incubated at $37^{\circ} \mathrm{C}$ for $90 \mathrm{~min}$. The mixtures were then transferred to the blocked N-cadherin wells on the microplate, and incubated at $37{ }^{\circ} \mathrm{C}$ for $2 \mathrm{~h}$. After washing, the collected fluorescent signal at $485 \mathrm{~nm}$ was subtracted the background signal by origin v9.0. 


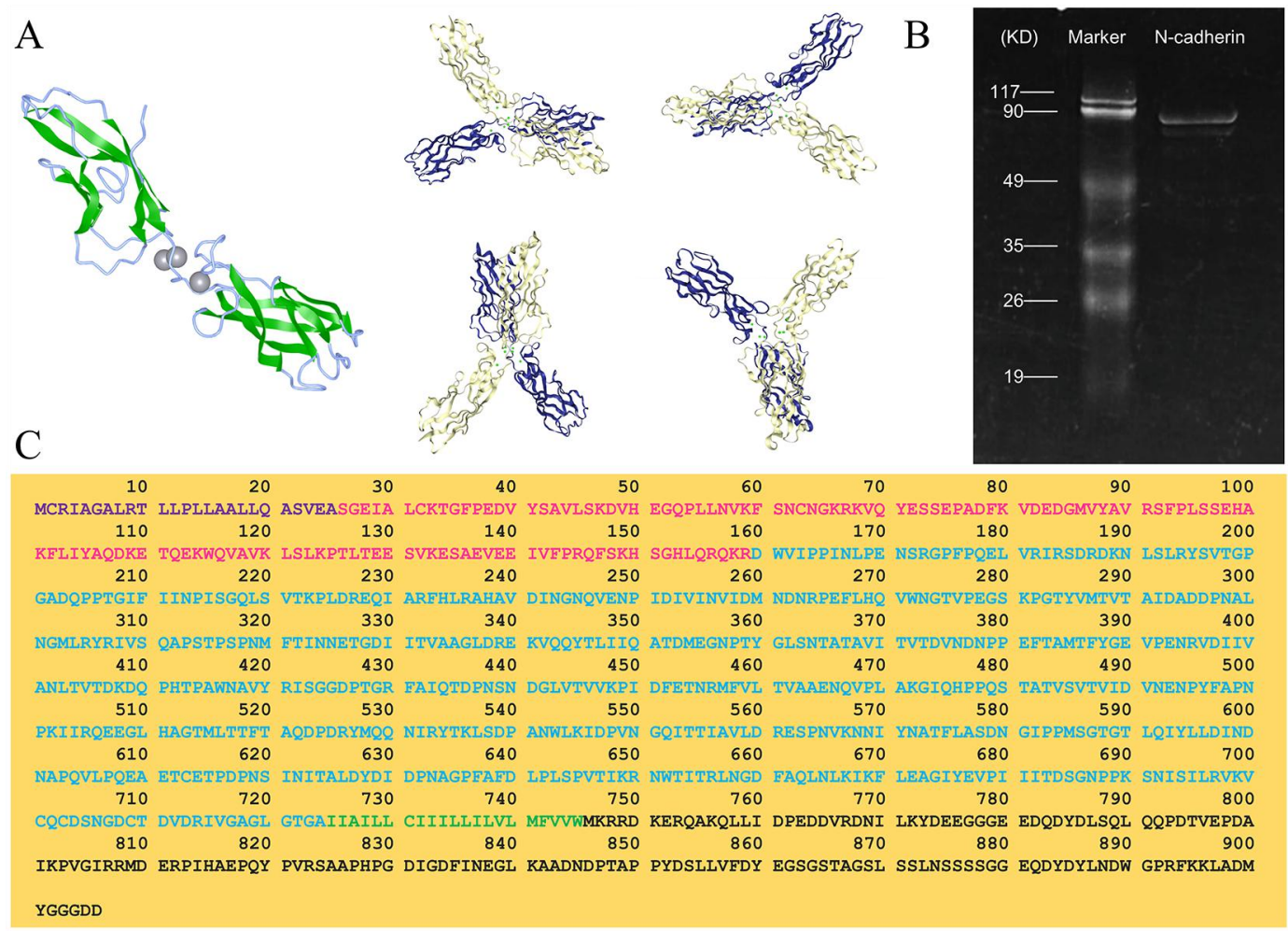

Figure S1. (A) The diagram of the structure of N-cadherin protein (left, PDB ID $2 \mathrm{QVI}^{3}$ ) and its assembly simulation in specific cell-cell recognition phenomena (right, PDB ID 4NUP $)^{5}$ (B) 10\% SDS-PAGE analysis of N-cadherin (C) The amino acid sequence of $\mathrm{N}$-cadherin

$\mathrm{N}$-cadherin has a total length of 906 amino acids, and positions $1-15$ at the $\mathrm{N}$-terminus are signal peptides (purple letters); positions 16-159 are propeptides (pink letters), positions 160-724 are the extracellular region (blue letters); positions $725-755$ are the transmembrane region (green letters); positions 746-906 are located in the cytoplasmic region (black letters). The DNA sequence (NP_001783.2) encodes the human N-cadherin extramembrane region Met1-Ala724 (red letters) and has a polyhistidine tag attached to the $\mathrm{C}$-terminus. The recombinant human $\mathrm{N}$-cadherin consists 710 amino acids and predicts a molecular mass of $78.5 \mathrm{kDa}$. 
Table S1. Selection parameters for N-cadherin protein

\begin{tabular}{|c|c|c|c|c|}
\hline Round & n(N-cadherin protein)/nmol & n(ssDNA pool)/pmol & PCR cycles & Incubation time (min) \\
\hline 1 & 60 & 2000 & 14 & $10 \times 3$ \\
\hline 2 & 30 & 1000 & 14 & $10 \times 3$ \\
\hline 3 & 15 & 800 & 12 & $10 \times 3$ \\
\hline 4 & 13.5 & 500 & 12 & $10 \times 3$ \\
\hline 5 & 12 & 450 & 12 & $10 \times 3$ \\
\hline 6 & 10.5 & 400 & 12 & $10 \times 3$ \\
\hline 7 & 9 & 350 & 10 & $8 \times 3$ \\
\hline 8 & 7.5 & 300 & 10 & $8 \times 3$ \\
\hline 9 & 6 & 300 & 10 & $8 \times 3$ \\
\hline 10 & 3 & 300 & 9 & $8 \times 3$ \\
\hline 11 & 2.4 & 200 & 8 & $5 \times 3$ \\
\hline 12 & 1.5 & 150 & 8 & $5 \times 3$ \\
\hline
\end{tabular}




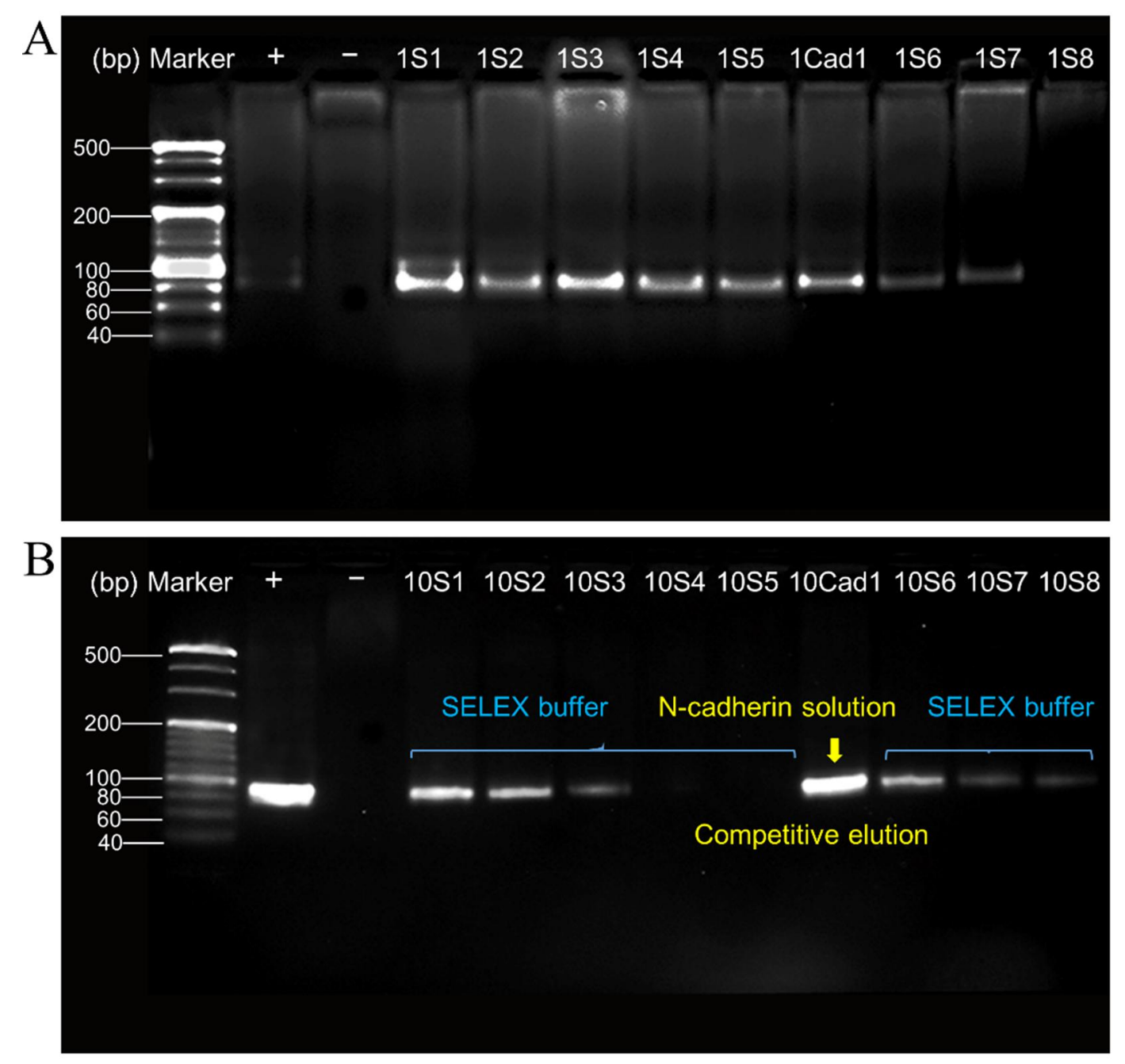

Figure S2. Agarose gel electrophoresis imaging for the 1st (A) and 10th (B) round of selection

The nS bands represent the PCR products amplified from the fractions washed by SELEX buffer, the nCad1 bands represent the PCR products amplified from the fractions eluted by N-cadherin solution, and $\mathrm{n}$ represents the SELEX round. 


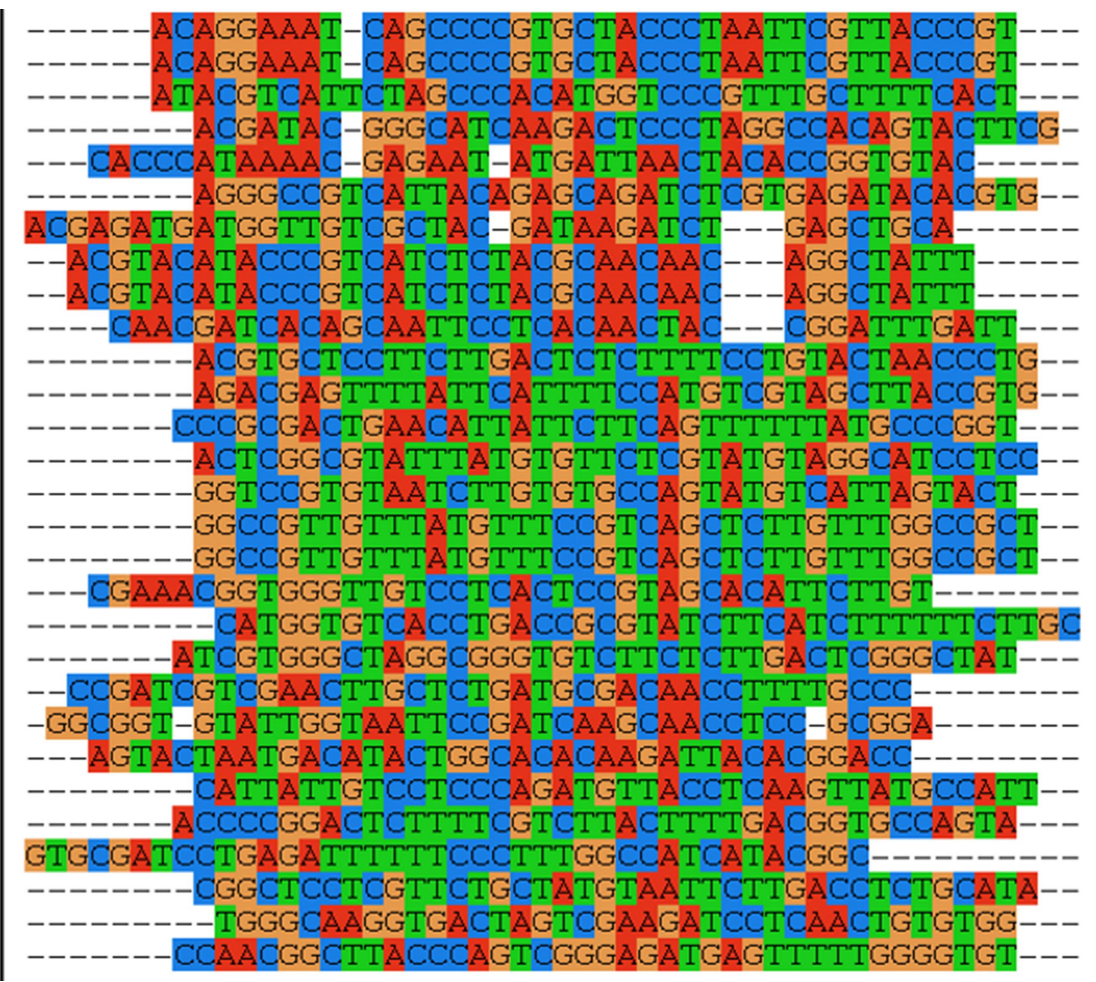

Figure S3. Sequence alignment results analyzed by ClustalX 1.8.3 software

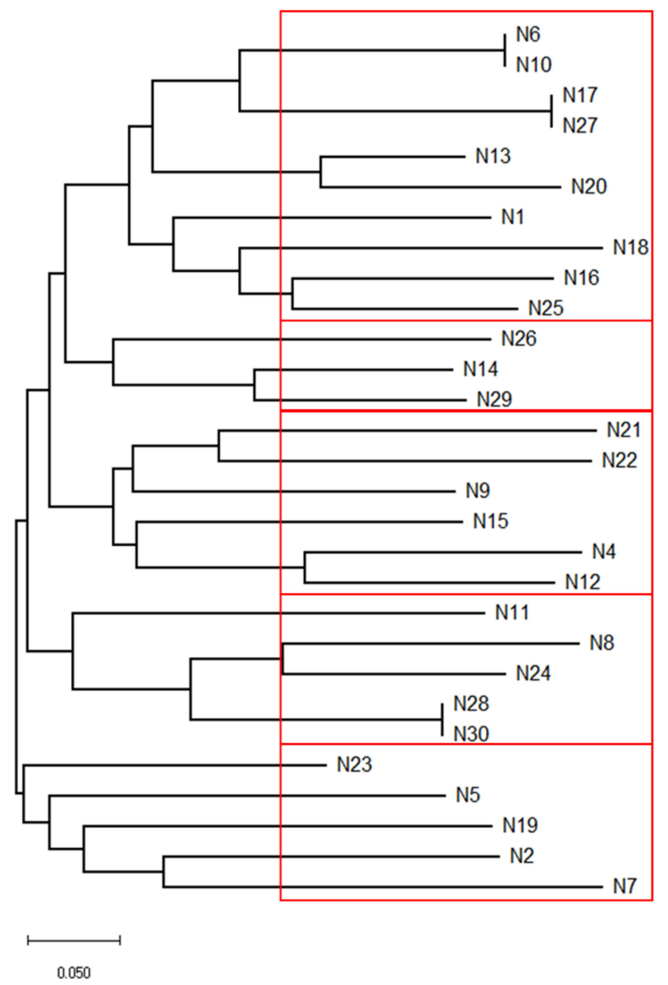

Figure S4. Molecular evolutional genetic analysis by Mega X10.0.5 software 


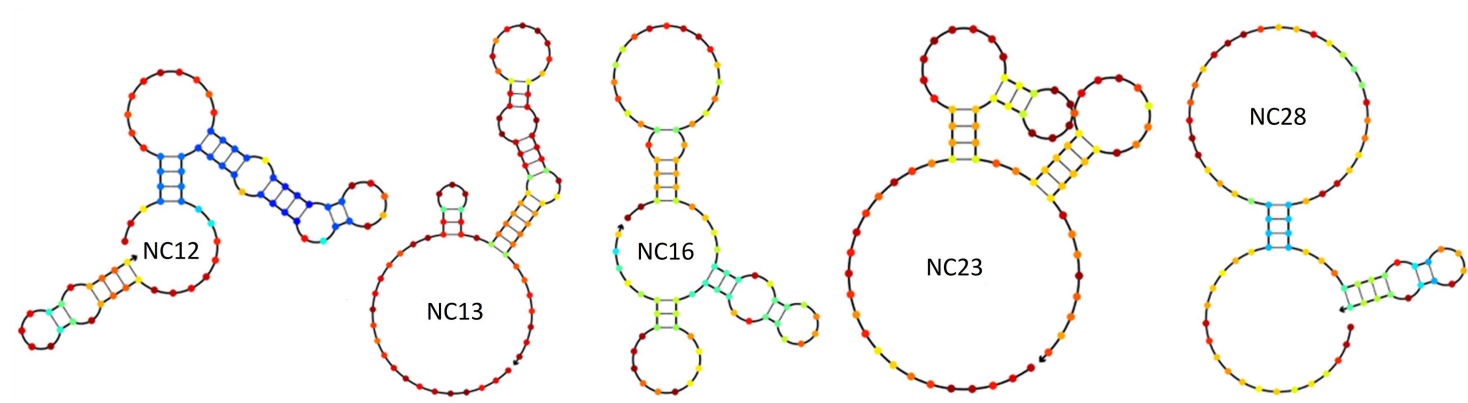

Figure S5. The predicted secondary structures for the five aptamer candidates by

NUPACK (http://www.nupack.org/).

\section{REFERENCES}

(1) Yang, L.; Ding, P.; Luo, Y.; Wang, J.; Lv, H.; Li, W.; Cao, Y.; Pei, R. Exploration of catalytic nucleic acids on porphyrin metalation and peroxidase activity by in vitro selection of aptamers for N-methyl mesoporphyrin IX. ACS Comb. Sci. 2019, 21, 83-89.

(2) Luo, Z.; He, L.; Wang, J.; Fang, X.; Zhang, L. Developing a combined strategy for monitoring the progress of aptamer selection. Analyst 2017, 142, 3136-3139.

(3) Davila, S.; Liu, P.; Smith, A.; Marshall, A. G.; Pedigo, S. Spontaneous calcium-independent dimerization of the isolated first domain of neural cadherin. Biochemistry 2018, 57, 6404-6415.

(4) Vendome, J.; Felsovalyi, K.; Song, H.; Yang, Z.; Jin, X.; Brasch, J.; Harrison, O. J.; Ahlsen, G.; Bahna, F.; Kaczynska, A.; Katsamba, P. S.; Edmond, D.; Hubbell, W. L.; Shapiro, L.; Honig, B. Structural and energetic determinants of adhesive binding specificity in type I cadherins. Proc. Natl. Acad. Sci. 2014, 111, e4175-e4184.

(5) Sehnal, D.; Rose, A.; Koča, J.; Burley, S.; Velankar, S. Mol*: towards a common library and tools for web molecular graphics MolVA. EuroVis Proceedings 2018. 